If $\alpha$ has a value (for a two-tailed test) of 0.025 the values of $\beta$ for sample sizes from 10 to 100 are:

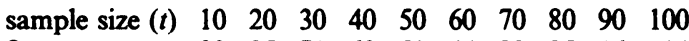
$\begin{array}{llllllllllll}\beta & 98 & 85 & 71 & 60 & 51 & 44 & 29 & 25 & 16 & 14\end{array}$

Thus, even with 60 schizophrenic offspring, which on our assumptions would require an initial cohort of 2000 index and 2000 control mothers, there would still only be a $56 \%(100-44)$ chance of detecting a significant result. And to have at least a $75 \%(100-25)$ chance of detecting a doubling of the risk of having a schizophrenic child more than 80 schizophrenic offspring would be needed, which would require an initial cohort of at least 2700 index and 2700 control mothers.

It is apparent, therefore, that the size of the cohort studied by Cannon et al $(n=80)$ was hopelessly inadequate. Similar criticisms apply to an earlier study of similar design by Crow \& Done (1992). Even though they had 945 mothers with a history of a flu-like illness in the second trimester of pregnancy they only had 7 schizophrenic offspring.

Cannon et al are right to point out that ecological studies of the kind that we and others have performed cannot by themselves establish an aetiological role for maternal influenza, because it remains unknown which, or even what proportion of, pregnant women actually contracted influenza. They are quite wrong, though, to suppose that their negative findings, or those of Crow \& Done, weaken that evidence.

Cannon, M., Cotter, D., Coffey, V. P., et al (1996) Prenatal exposure to the 1957 influenza epidemic and adult schizophrenia: a follow up study. British Journal of Psychiatry, 168, 368-371.

Crow, T. J. \& DONE, D. J. (1992) Prenatal exposure to influenza does not cause schizophrenia. British Journal of Psychiatry, 161, 390-393.

WoOdGATE, M. \& CURTis, D. (1996) Prenatal exposure to the 1957 influenza epidemic. British Journal of Psychiatry, 168, 791.

W. Adams

University of Edinburgh Medical School R. E. KENDELL Edinburgh EH8 9AF

\section{No evidence for association between CNTF null mutant allele and schizophrenia}

SIR: Recently, Thome et al (1996) reported data suggesting a possible association between a null mutated allele of the ciliate neurotrophic factor (CNTF) gene and endogenous psychosis in Caucasian individuals. CNTF is thought to be important for the survival of motor neurons (Sendtner et al, 1992). Disruption of the CNTF gene in mice causes motor neuronopathy (Masu et al, 1993). The null mutation in the human $C N T F$ gene producing a new splice acceptor site resulting in an aberrant protein has been found to be polymorphic in Japanese (Takahashi et al, 1994) and Caucasian (Thome et al, 1996) populations. Thome et al (1996) reported that the frequency of the mutant allele in psychiatric patients was significantly increased, compared with controls. We analysed the $C N T F$ genotypes of 205 unrelated Japanese patients with schizophrenia, aged 25-65 years (mean 48.9), who met DSM-III-R criteria for schizophrenia, and of 184 age and gender-matched unrelated Japanese controls, aged $31-65$ years (mean 50.1).

With our sample size, there was more than 0.98 chance of detecting an odds ratio of 2.28 at $\alpha=0.05$, one-sided. In our subjects, the distribution of the single genotypes in controls $\boldsymbol{v}$. schizophrenics was as follows. Normal: $65.6 \%$ v. $70.2 \%$; heterozygote mutant: $29.2 \%$ v. $27.3 \%$; homozygote mutant: $5.2 \%$ v. $2.4 \%$. The mutant allele frequencies in the schizophrenics and the controls were 0.16 and 0.18 , respectively (Odds ratio is $0.90,95 \%$ CI $0.62-1.32$ ). Thus, our subjects provided no evidence for an association between the CNTF null mutant allele and schizophrenia.

Masu, Y., Wolf, E., Holtmann, B., et al (1993) Disruption of the CNTF gene results in motor neuron degeneration. Nature, 365 , 27-32.

Sendtner, M., SChwalbruch, H., Stockl, K. A., et al (1992) Ciliary neurotrophic factor prevents degeneration of motor neurons in mouse mutant progressive motor neuronopathy. Nature, 358, 502-504.

Takahasin, R., Yokoj, H., Misawa, H., et al (1994) A null mutation in the human CNTF gene is not causally related to neurological diseases. Nature Genetics, 7, 79-84 (erratum 215).

THOME, J., KorNhUBer, J., BAUmer, A., et al (1996) CNTF and endogenous psychoses? Nature Genetics, $12,123$.

Institute of Basic Medical Sciences

T. Arinami

University of Tsukuba

Tsukuba, Ibaraki, 305, Japan

Tokyo Medical and Dental University

M. TORU

School of Medicine

Tokyo, 113, Japan

Should the administration of ECT during clozapine therapy be contraindicated?

SIR: There are only a few reports (Masiar \& Johns, 1991; Green et al, 1994) regarding the 
administration of ECT and clozapine. Although not officially contraindicated, due to the epileptogenous effect of clozapine, this combination is rarely used. Herein, we present a case that demonstrates this problematic issue.

An 18-year-old patient was admitted to our hospital due to a refractory psychosis. Under treatment with chlorpromazine, haloperidol, and levopromazine (for adequate time and dosage), there was no improvement. A course of ECT was started with limited results. After the 11th treatment, clozapine was added. During the 12th treatment (being under $50 \mathrm{mg} /$ day clozapine), he developed for the first time a prolonged seizure (6 minutes long which was terminated with diazepam). There were no residual neurological sequelae. The patient achieved a reasonable remission with clozapine.

This report demonstrates some of the problems accompanying the administration of ECT and clozapine (even in low doses). In view of the expanding use of clozapine in psychiatric practice, and the important role ECT has in treating affective disorders and psychosis, it seems appropriate to be aware of this complication.
Green, A. I., Zalma, A., Berman, I., et al (1994) Clozapine following ECT: a two step treatment. Journal of Clinical Psychiatry, 55, 388-390.

MasinR, S. J. \& Johns, C.A. (1991) ECT following clozapine (letter). British Journal of Psychiatry, 158, 135-136.

Y. BLOCH

M. Pollack

I. MOR

Shalvata Mental Health Center

Hod Hasharon

P.O. Box 94, Israel

\section{Train of thought continued}

SIR: Robert Goodman's letter (BJP, April 1996) about trainspotting made me think, as organiser of our local Senior Registrar scheme, about trainers. Much has been written about training trainees and training the trainers but who trains the trainees' trainers' trainers or the trainees' trainers' trainers' trainers. If anyone spots them I would offer to train them.

Withington Hospital

A. BURNS

Manchester M20 8LR

\section{A HUNDRED YEARS AGO}

\section{Hospital and Dispensary Management BETHLEM Hosprtal}

New Recreation Hall - His Royal Highness the Duke of Cambridge opened the new Recreation Hall at Bethlem Hospital on June 9th in the presence of a numerous company. His Royal Highness was accompanied by Sir James Clarke Lawrence, Bart., who explained the advantages the patients would derive from being at last provided with what had been so long felt to be necessary for their welfare and a valuable adjunct to treatment. His Royal Highness before proceeding to declare the hall open, dwelt upon the past history of the institution and the great benefit it had been to the community, and appealed to the audience to help in clearing off the debt which remained. After declaring the hall opened the wards were visited and refreshments served. The hall is lofty, handsome, and admirably suited for the purpose, measuring something like 60 feet by 40 , and having a large and commodious stage with the necessary dressing rooms, etc., fitted up at the end. It is stated to have cost about $£ 10,000$.

\section{Reference}

British Medical Journal, June 1896, 1484. 